\title{
Morphology and physiology of the epiphyseal growth plate
}

\author{
Franciszek Burdan'1, Justyna Szumiło², Agnieszka Korobowicz ${ }^{3}$, Rabia Farooquee ${ }^{1,4}$, \\ Sagar Patel1,4, Ankit Patel1,4, Anjalee Dave1,4, Michal Szumilo5, Michał Solecki'1, \\ Robert Klepacz ${ }^{2}$, Jarosław Dudka ${ }^{2}$
}

\author{
${ }^{1}$ Experimental Teratology Unit of the Human Anatomy Department, Medical University of Lublin, \\ Lublin, Poland \\ ${ }^{2}$ Clinical Pathomorphology Department, Medical University of Lublin, Lublin, Poland \\ ${ }^{3}$ Pediatric Pulmonology and Rheumatology Department, Medical University of Lublin, Lublin, Poland \\ ${ }^{4}$ Hope Medical Institute, Newport News VA, USA \\ ${ }^{4}$ Applied Pharmacy Department, Medical University of Lublin, Lublin, Poland
}

\begin{abstract}
The epiphyseal growth plate develops from the cartilaginous-orientated mesenchymal cells that express SOX family genes. This multilayer structure is formed by the proliferation and hypertrophy of cells that synthesize the extracellular matrix composed of collagen (mainly type II, IX, X, XI) and proteoglycans (aggrecan, decorin, annexin II, V and VI). The resting zone is responsible for protein synthesis and maintaining a germinal structure. In the proliferative zone, cells rapidly duplicate. The subsequent morphological changes take place in the transformation zone, divided into the upper and lower hypertrophic layers. In the degenerative zone, the mineralization process becomes intensive due to increased release of alkaline phosphate, calcium and matrix vesicles by terminally differentiated chondrocytes and some other factors e.g., metaphyseal ingrowth vessels. At this level, as well as in the primary and secondary spongiosa zones, chondrocytes undergo apoptosis and are physiologically eliminated. Unlike adult cartilage, in fetal and early formed growth plates, unusual forms such as autophagal bodies, paralysis and dark chondrocytes are also observed. Their ultrastructure differs greatly from apoptotic and normal cartilage cells. Chondrocyte proliferation and differentiation are regulated by various endocrine, paracrine, and autocrine agents such as growth, thyroid and sex hormones, beta-catenin, bone morphogenetic proteins, insulin-like growth factor, iodothyronine deiodinase, leptin, nitric oxide, transforming growth factor beta and vitamin D metabolites. However, the most significant factor is parathyroid hormone-related protein (PTHrP) which is synthesized in the perichondrium by terminally differentiated chondrocytes. Secondary to activation of PTH/PTHrP receptors, PTHrP stimulates cell proliferation by $\mathrm{G}$ protein activation and delays their transformation into prehypertrophic and hypertrophic chondrocytes. When proliferation is completed, chondrocytes release Indian hedgehog (Ihh), which stimulates PTHrP synthesis via a feedback loop. Any disturbances of the epiphyseal development and its physiology result in various skeletal abnormalities known as dysplasia.
\end{abstract}

Key words: epiphyseal growth plate, cartilage, chondrocyte, cell differentiation, calcification, bone development, dark chondrocytes, paralysis chondrocytes

\section{Introduction}

Mammalian growth plate, also known as epiphyseal plate or physis, is highly specialized mesodermderived cartilaginous structure. It develops in the bone bud, secondary to presence of the primary ossification centers and is responsible for bone elongation. The

Correspondence: F. Burdan, Experimental Teratology Unit of the Human Anatomy Dept., Medical University of Lublin, 4 Jaczewskiego Str. PL-20090 Lublin, Poland;

tel.: (+48) 603767649; fax.: (+4881) 5328903, e-mail: fb3@wp.pl plates are formed by numerous cells that rapidly divide and mature. Post puberty, the epiphyseal cartilage cell division decreases, bone completely replaces cartilage, and the epiphyseal plates fuse together with primary and secondary ossification centers $[1,2]$.

\section{Cartilage differentiation process}

Presently, four major stages of chondrocyte differentiation are known, i.a., mesenchymal precursor cells (MPCs), prechondrocytes, early chondroblasts and terminally differentiated chondrocytes [1-4]. 
The initial steps in cartilage formation are secondary to condensation of mesenchymal cell from 12 to 15 per $1000 \mu \mathrm{m}^{2}$. MPCs initiate chondrogenesis by first migration to presumptive skeletogenic sites from the cranial neural crest, paraxial mesoderm, and lateral plate mesoderm and formation of cell mass condensations [3,5]. MPCs divide in the center of the condensations to form prechondrocytes that turn off the expression of mesenchymal and condensation markers. Instead of an elongated shape they become rounder with concomitant decrease of intercellular adhesion and intensive endothelial cell proliferation [6]. Such process is highly dependent on N-catherin and the presence of glycosaminoglycans, which synthesis stops at the end of cellular condensation [7]. Mesenchymal-endothelial junctions are stabilized by fibronectin, the synthesis of which is stimulated by transforming growth factor $\beta$ (TGF $\beta$ ) [8]. The following steps depend on syndecan-3 which requires transformations from mesenchymal condensation to direct skeleton development and prohibits the mesenchyme over-proliferation [3,9]. Simultaneously, most of the primary vessels disappear, and only those stimulated by vascular endothelial growth factor (VEGF) persist [5]. Secondary to transcriptional factor Runx2, mesenchymal cells commences synthesis of collagen type I, osteocalcin, osteonectin and osteopontin. Such primary selected cells are characterized by high expression of gene coded bone morphogenetic protein 6 (BMP6). In contrast, cells predominately directed to cartilage development have high expression of Sox family genes that regulate synthesis of collagen type II and its isoform IIa1, as well as collagen IXa1 and XIa2 $[3,10,11]$. Sox 9 plays a crucial role in the chondrogenesis initiation [12]. However, it was already proven that due to unknown molecular mechanism, some cells with Sox expression may develop to osteoprogenitor cells [13]. Differentiation of prechondrocytes leads to active chondrogenic cells called chondroblasts, which rapidly proliferate and build new bone tissue. They expressed $\operatorname{Sox} 9$ which is required for further differentiation [14]. Sox9 is highly expressed in prechondrocytes and chondroblasts, however, once the cells undergo prehypertrophy or hypertrophy, the gene turns off [15]. In the study of Akiyama et al. [12] inactivation of Sox9 using Prx1Cre transgene, a gene expressed in early limb bud mesenchymal cells, resulted in lack of appendicular cartilage elements in embryo. Such observations have suggested that transcription factors have been identified to control mesenchymal cell migration, proliferation, survival, and condensation in one or a subset of cartilage elements. These elements control the skeletal development in multiple species and are also referred to as patterning factors since they determine the shapes and sizes of the skeletal elements $[1,14]$.
Prechondrocyte differentiation leads to the next stage, known as early chondroblasts. Early chondroblasts develop cartilage growth plates by assuming a flattened shape and organizing into longitudinal columns. They proliferate at a high rate until, one layer at a time; they exit the cell cycle and start to increase in size, undergoing prehypertrophy followed by full hypertrophy. They undergo apoptosis to allow primary ossification centers to expand. Cells located in the middle of the epiphysis of future long bones undergo a similar maturation process that leads to the formation of secondary ossification centers $[1,2,16]$.

Chondrocytes are metabolically active cells that synthesize various elements of the extracellular matrix (ECM) [17] They are also a source of so called matrix vesicles, $100 \mathrm{~nm}$ in diameter-follicles, formed by separation of cellular membrane $[4,18,19]$. The calcium accumulation in matrix vesicles seems to be directly related to calcium channel molecules - annexin II, V and VI that are found in the external lipid bilayer of the vesicles. Collagens type II and X bind to matrix vesicles and, in turn, interact with the annexin V [20]. The role of type $\mathrm{X}$ collagen, primarily found in the hypertrophic zone (see below), is to facilitate the deposition of calcium within the matrix [21]. Some other matrix elements are also involved in this process mostly proteoglycans, e.g., aggrecan which aids in the osmotic properties that are essential for resisting compressive loads, as well as decorin that regulates collagen fibrillogenesis. On the contrary, cartilage oligomeric protein is a non-collagenous calcium binding glycoprotein found in the ECM [22].

\section{Growth plate morphology and physiology}

Each growth plate is a sandwich-like, multilayer structure divided into four well defined zones: reserve, proliferative, transformation and degeneration (Fig. 1). The last zone is adjusted to the primary spongiosa zone that finally gives origin for the secondary spongiosa zone.

Resting cartilage cells lying within the reserve zone (also known as resting or germinal zone) are formed by small, uniform, compactly located chondrocytes that occur singly or in pairs and are rich in lipid and cytoplasmic vacuoles (Fig. 2A). Additionally, in the zone ECM take more place than cells [1]. This zone is characterized also by low rates of proliferation and proteoglycan and collagen type IIB synthesis $[1,13]$. It is surrounded the groove of Ranvier, that hosts chondrocyte progenitor cells, which flow into the cartilage of this germinal layer $[1,22]$.

The direct continuation of the reserve zone is the second layer known as proliferative zone. Its chondrocytes are flat and well divided into longitudinal columns (Fig. 2B). The mitotic activity is found only 


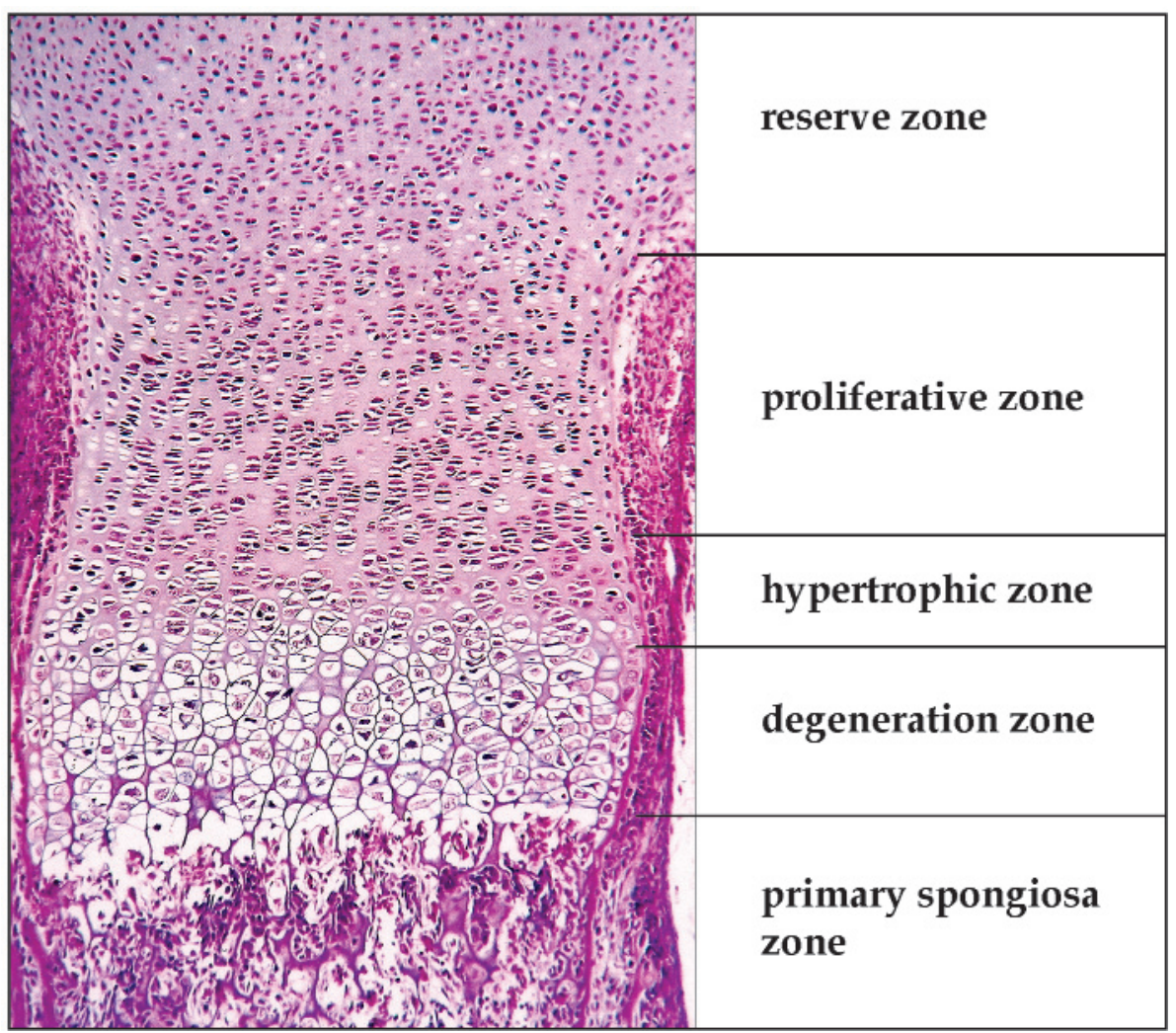

Fig. 1. Longitudinal section of the proximal femoral epiphysis from 21-day-old rat pup $(\mathrm{H}+\mathrm{E}$, original magnification $\times 100)$. in the base of the columns. This true germinal layer has increased type II and type XI collagen synthesis [22].

Below the proliferative zone is another layer known as transformation zone, divided into upper and lower hypertrophic zone and a farther located degeneration zone. The most characteristic feature of chondrocytes of this level is lack of cellular division and decreased DNA synthesis. Instead of proliferation the cells synthesize high amount of various elements of ECM. It is worth to mention that this is the only zone that contains short-chain collagen and the first to produce alkaline phosphatase, responsible for the widening of the growth plate by increasing phosphate ions that are required for calcification $[1,2,22]$. Compared to the other zones chondrocytes of transformation one are relatively larger. They begin to terminally differentiate and become swollen (Fig. 2C and 2D). Closer to the primary spongiosa zone the amount of cells with features of degeneration increases. Chondrocytes lose intercellular junctions and are located in special vesicles formed by ECM [1].

Major phenotypic changes occur when chondroblasts divide into prehypertrophic and hypertrophic chondrocytes. Cytoplasmic volume increases ten times and levels of mRNA increase for most early cartilage matrix genes [14]. Once they reach the hypertrophic stage, they no longer express early cartilage matrix genes. Cells located centrally to the cartilage anlagen differentiate directly to prehypertrophy from pre- chondrytic or early chondroblastic stage $[1,14,17]$. This process is regulated by genes Sox $5 /$ Sox6. These genes function is to hinder the prehypertrophy rate and to promote hypertrophy [23].

Chondroblast columnar proliferation is also assisted by a transcriptional activator of the Runt domain. This domain holds the activator Runx 2 which directs organization of columns by influencing chondroblast proliferation. Runx2 is expressed in chondrogenic mesenchymal cells and hypertrophic and terminally differentiated chondrocytes but is inactivated in chondroblasts [24]. Runx2 and Runx 3 both induce chondrocyte prehypertrophy and hypertrophy. When Runx2 was expressed in chondroblasts of transgenic mice, the cells showed ectopic maturation, however, when the negative form was expressed in the same cells, events of prehypertrophy followed [25]. Therefore, it seems that Runx2 is a direct transcriptional activator of chondrocyte maturation markers.

The maturation of chondrocytes is due to physical and biochemical changes that occur in a spatial and temporal pattern. In differentiation, there is a 5-10-fold increase in intracellular volume, which is not a passive swelling. Instead, it is an active process by which there is an increase in organelles such as mitochondria and the endoplasmic reticulum $[5,26]$. The chondrocytes located in bones with rapid growth such as the femur, increase at a faster pace than chondrocytes in bones, like the radius, primarily due to the proportions of size [27]. 

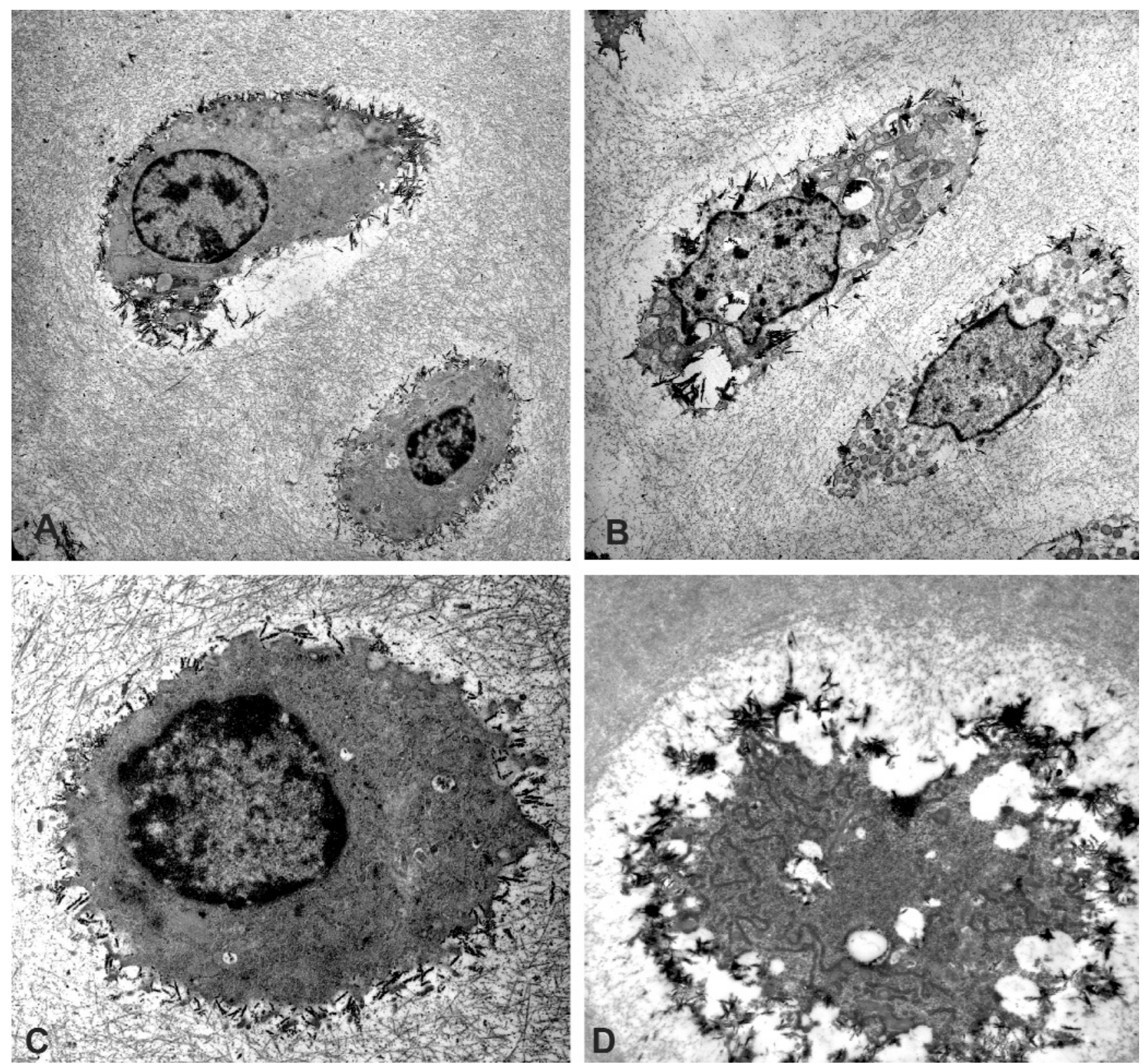

Fig. 2. Chondrocytes of the reserve (A), proliferative (B), hypertrophic (C), and degenerative (D) zones of the proximal femoral epiphysis from the 7 -day-old rat pup (TEM, original magnification $\times 3000$ ).

Despite of above mentioned alkaline phosphate, one of the most important factors for chondrocyte hypertrophy and terminal differentiation is the transcription core binding factor 1 (CBFA1) [25]. However in mice lacking CBFA1 in their growth plate, normal hypertrophy is observed, which indicates that other transcription factors like Smad-1, -5 and -8 also play an important role in this process $[25,28,29]$.

The morphology of the lowest zone - primary spongiosa - is similar to the lower level of degeneration zone. However, it is characterized by presence of osteoprogenitor cells. Due to initiation of mineralization process, primary ossified bone lamella and small blood vessels are also visible $[1,2,22]$.
As hypertrophy shifts to terminal differentiation, the gene Colloal ceases to be expressed in chondrocytes leading to the activation of a new group of genes [14]. They induce extracellular matrix mineralization and as current view states, they result in cell death, or apoptosis. The importance of a terminally differentiated chondrocyte seems to be the preparation of calcification by the matrix; since once the cartilage calcifies, apoptosis is required to remove the terminally differentiated chondrocytes. After the cartilage has undergone calcification, the removal of differentiated chondrocytes allows for access by the vascular channels and bone-marrow stromal cells [30-35]. Chondrocytes in the hypertrophic zone have similar morphological 
Table 1. Basic morphological features in various types of programmed cell death of chondrocytes (based on Roach and Clarke [44] with own modification).

\begin{tabular}{|c|c|c|c|}
\hline & $\Lambda$ poptosis & Dark chondrocyte & Paralysis chondrocyte \\
\hline Nucleus & $\begin{array}{l}\text { rounded nucleus; chromatin condensation } \\
\text { into rounded bodies, crescent or caps } \\
\text { marginated to the nuclear envelope; } \\
\text { fragmentation of nucleus and formation of } \\
\text { apoptotic bodics; digestion during } \\
\text { phagocytosis of apoptotic bodies by nearby } \\
\text { cells; chromatin condensation before or } \\
\text { simultaneously with cell shrinkage }\end{array}$ & $\begin{array}{l}\text { dark nucleus with convoluted } \\
\text { outlines; chromatin condensation } \\
\text { into small "patches" located } \\
\text { throughout the nucleus; prominent } \\
\text { nuclcolus; chromatin condensation } \\
\text { after or simultaneously with } \\
\text { secretion and vacuolization }\end{array}$ & $\begin{array}{l}\text { dark nucleus with convoluted } \\
\text { outlines; chromatin } \\
\text { condensation into small } \\
\text { "patches" located throughout the } \\
\text { nucleus; chromatin condensation } \\
\text { after cytoplasmic digestion }\end{array}$ \\
\hline Cytoplasm & $\begin{array}{l}\text { condensed; formation of apoptotic bodies; } \\
\text { digestion during phagocytosis of apoptotic } \\
\text { bodies by nearby cells }\end{array}$ & partly digested within cell & $\begin{array}{l}\text { enclosed and replaced by } \\
\text { expanded rough endoplasmic } \\
\text { reticulum; digestion of } \\
\text { cytoplasmic "islands" with } \\
\text { formation of "worm-like" } \\
\text { structures }\end{array}$ \\
\hline Tysosoms & intact within apoptotic bodies & probably intact & $\begin{array}{l}\text { digested within intracellular } \\
\text { "islands" }\end{array}$ \\
\hline $\begin{array}{l}\text { Other } \\
\text { organelles }\end{array}$ & $\begin{array}{l}\text { apparently intact but condensed; formation } \\
\text { of apoptotic bodies; digestion during } \\
\text { phagocylosis of apoptotic bodies by nearby } \\
\text { cells }\end{array}$ & $\begin{array}{l}\text { well developed Golgi complex and } \\
\text { endoplasmic reticulum, matly } \\
\text { secrelory vesicles and large } \\
\text { mitochondria }\end{array}$ & $\begin{array}{l}\text { distension of rough endoplasmic } \\
\text { reticulum with formation of } \\
\text { cyloplasmic "islands" } \\
\text { containing organclles and their } \\
\text { digestion; small dark inclusions, } \\
\text { secretory vesicles, Golgi } \\
\text { complex and swollen } \\
\text { mitochondria }\end{array}$ \\
\hline $\begin{array}{l}\text { Ccll } \\
\text { metnbrane }\end{array}$ & $\begin{array}{l}\text { budding - formation of large cyloplasmic } \\
\text { protuberances to produce apoptotic bodies } \\
\text { (late event) }\end{array}$ & $\begin{array}{l}\text { extensive blebbing - formation of } \\
\text { small protuberances to produce } \\
\text { vesicle-like structures (all stages) }\end{array}$ & blebbing (late event) \\
\hline
\end{tabular}

characteristic to other cells undergoing apoptosis such as the condensation of the nuclear chromatin, cell shrinkage, and plasma membrane blebbing $[1,4,9,22]$.

It should be noted, that early growth plate - visible before the secondary ossification centers are formed is an avascular structure which relies on receiving nutrients and oxygen via diffusion from the vascular arcades presented in the metaphyseal side of the epiphysis [31]. The anatomical location of the vascular channels is between the calcified cartilages under the last row of hypertrophic chondrocytes [30]. VEGF is the key factor responsible for vascular ingrowths, which is physiologically expressed solely by the hypertrophic chondrocytes $[5,22]$.

\section{Physiological chondrocytes elimination}

Chondrocytes similar to most other mammalian cells are physiologically eliminated via programmed cell death. However, unlike in other greatly vascular tissues, removal of apoptotic bodies is difficult due to large amounts of ECM, and is only possible in the primary spongiosa zone $[4,9,33,34]$.

Typically apoptotic cells are characterized by nuclear chromatin condensed into dark crescents, caps, spheres, and smaller so called shrinks size. Such changes are secondary to DNA fragmentation and intracellular disintegration. The cells and apoptotic bodies are typical for adult cartilage; however, rapidly undergo phagocytosis [36]. In fetal and early formed growth plates, some other types like authophagal bodies, paralysis and dark chondrocytes are also observed (Table 1) [4,18,32].

\section{Authophagal bodies}

It was found that morphology of some hypertrophic chondrocytes was diverse that of apoptic cells with irregular nuclei and an exaggerated endoplasmic reticulum [37]. These cells were unable to live or die analogous to a paralytic state, a form of cell death similar to dark chondrocytes (see below). These cells underwent autophagy $[38,39]$ that is a process that involves the cell using its own components to degrade itself by lysosomes. These cells contain double-membrane autophagic vacuoles, termed autophagosomes that are used for self degradation. Autophagy protects the cells by consuming its own lipids and nutrients to generate energy when nutrients are deficient [40]. Protein Tor is the main component involved in detection of nutrients 
concentration. It blocks autophagy when nutrients are available [41,42]. A negative regulator of Tor protein is AMP-dependent protein kinase associated with the cell redox status, which blocks Tor complex. Autophagy is also regulated by low oxygen and/or low protein levels. Additionally, low glucose level signals glycolysis which lowers ATP and use of nutrients, promoting autophagy [42].

\section{Paralysis chondrocytes}

The paralysis chondrocytes develop secondarily to the focal digestion of cytoplasm and organelles that occurs within an internal "island" formed by an enlarged and highly hydrated lumen of the endoplasmic reticulum [43]. The next step in cellular disintegration is always chromatin condensation with formation of typical small patches throughout the nucleus that usually has a convoluted outline. Similar to other types of programmed cell death, and unlike necrosis, release of proteolytic enzymes has not been observed. In the late stages, formation of small, blister-like, vacuolated structures from pseudopodias, which is presently known as blebbing is observed. Elimination of paralysis and dark chondrocytes are probably similar and will be explained below $[33,43,44]$.

\section{Dark chondrocytes}

In the last few decades numerous authors have reported a presence of chondrocytes which have a different morphology from so-called normal (light) cells in the same growth plate zone. Due to their characteristic images in transmission electron microscope (TEM) they are known as dark chondrocytes (Fig. 3) $[4,18]$.

Dark chondrocytes have different signs of degeneration, like the separation of a nucleolus "cap", single blebs of plasmalemma, and are also seem to be more viable. The typical nucleus of a dark cell includes the tandemic arrangement of chromatin condensations, large, compact, nucleolus, and undeveloped accessory nucleoli. Contrary to them, light chondrocytes possess evenly shaped nuclei with dispersed chromatin. As dark cells become more advanced, the density of their karyoplasms increases and condenses into chromonema-like strands or irregular clumps (less often). Both light and dark cells usually contain one or two centrally located nucleoli of differing types, the "compact nucleolus". However, in more advanced dark cells, the nucleoli appeared to be hyper-compacted and smaller, suggesting degeneration. It is worth mentioning that their nuclear membrane often contains defects. The segments ravel into small inverted buds and dissolve together with adjacent chromatic clumps to release pore complexes $[4,18,33,38]$.

It should be stressed that such cells have a particular path of division. They are not present in normal mitosis, but only sandwich-like amitotic nuclear segregation. Their nuclei commonly lose nucleoli and hyper-compact, after which they dissolve. Additionally, such cells have a chromatic arrangement similar to that of condensed pro-metaphase or metaphase. These lack nucleoli, but are surrounded to some extent by a nuclear membrane. Sometimes, microtubules are located between lobes of chromatin clumps that resemble chromosomes. This pattern has been identified in some tumor and irradiated cells and is known as a "clover leaf" $[38,45]$. Similarly, the metaphase-like chromatin figures in interphasic cells are also found on cell imprints. All forms that look like division have characteristics of aberrancy, i.a., minimal, to a lack of spindle elements, maintain nuclear membrane, hypercompaction and chromatin dissolution $[38,46]$.

Unlike light chondrocytes that have small mitochondria and sparse rosettes of glycogen, dark cells are characterized by plenty of glycogen and large swollen mitochondria with well developed cristae, which occasionally possess fenestrae and dark matrix. The Golgi complex is the dominant organelle. At times, even the nucleus appears as an enlarged "belly" of the Golgi. In some locations, it appears as if the entire cisternae are destined to rupture or protrude to the exterior of the cell. Besides, multiple invaginations of the ground cytoplasm in the dilated cisternae are found. Such cells contain also ribosomes and form "inverted channels". The cell membrane blebbing (zeiosis) is also typical of dark cells and less often the cytoplasm is disintegrated. Such membrane fragmentation gives origin to the above mentioned matrix vesicles $[18,38,46]$.

It should be noted that there are also nuances in dark cells during their transitional phase. Cells which appear to be transitory are observed only in early embryos. Arguably these cells could be transitioning, just as likely, from dark to light chondrocytes. These cells have two distinct characteristics of dark cells-pattern of chromatic compactions and "inverted" membrane, but their karyoplasm and ground cytoplasm are not condensed $[4,18,38]$.

Dark cells also exhibit atypical characteristics during cell death. At times, these small dark cells resemble apoptotic ones, however, they do not have typical condensed chromatin. There were two different degeneration patterns: one where the karyolitic dark cell forms a pair with a normal chondrocyte in the proliferating zone, and in the resting zone, the karyopycnotic dark cell is engulfed by a light chondrocyte. The generally accepted hypothesis states that elimination of dark cells or their remnants occurs in the lower primary spongiosa zone due to phagocytosis. However, in the upper part of the growth plate, the cell size reduces and their matrix lacuna becomes smaller secondary to a higher secretion of ECM elements and the release of matrix vesicles. This explains the high number of empty lacunas observed in 

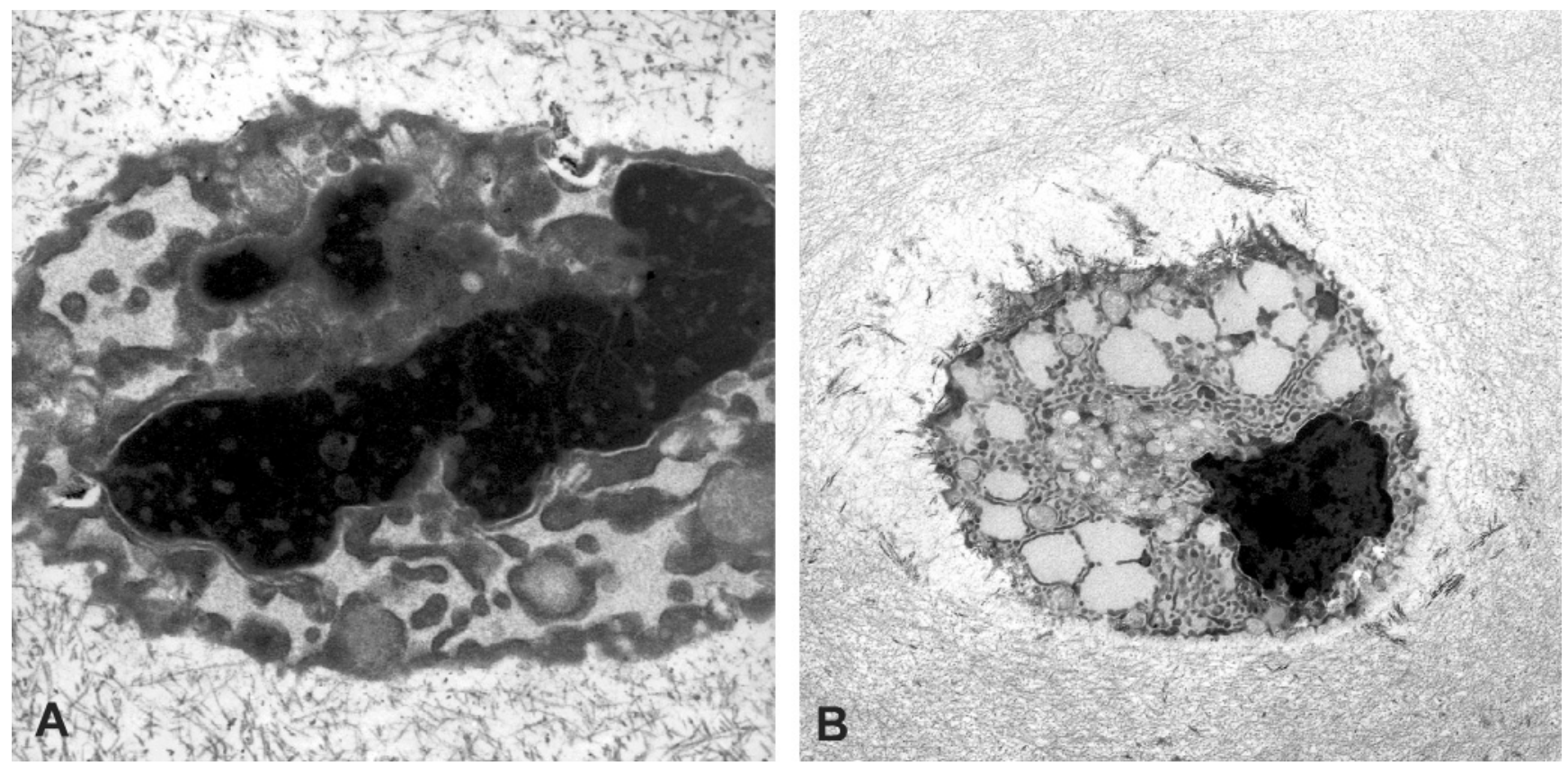

Fig. 3. Apoptotic (A) and dark (B) chondrocytes of the hypertrophic zone of the proximal femoral epiphysis from the 21-day-old rat fetus and 7-day-old rat pup, respectively (TEM, original magnification $\times 3000$ ).

various developmental studies. The second mechanism seems to be prominent in the proliferative zone, where the cell space is taken up by the expansion of the ECM around neighboring chondrocytes $[4,43,46]$.

Until now, dark chondrocytes were reported only in human fetal cartilage [46], mice mandibular condyle [48], physes of piglets [49], proximal epiphyses of the femur and humerus in young (0-9 day, and 5- and 20 weeks old) New Zealand rabbits [33], proximal femoral growth plate of 14-15 day chick embryos $[4,38]$, as well as 21-day old fetuses [18] and 7-day old pups of Wistar rats [50]. Dark chondrocytes were present in about $10-35 \%$ of avian embryos growth plates and were found in all stages of chondrocyte differentiation and in all ages of studied femurs. In every zone, such cells were revealed to be juxtaposed to light ones. They were even observed in mineralized areas with signs of degeneration, and found to be abundant in proliferating cells. Sporadically, they were even seen sharing a common lacuna $[4,38]$. Unlike those findings, such dark cells were present only occasionally in rat offsprings [18]. Among the six proximal epiphyses of the fetal femur, they were found only in four separate specimens. The prenatal fetuses exposed to various cyclooxygenase inhibitors, possessed dark chondrocytes in 23 out of the 32 examined samples, without any association with administered drugs. Similar frequency and the same localization of dark cells, limited to the germinal and proliferative zones, were later reported by Solecki [50]. The last two cited reports are the only fully available ones that presents such chondrocytes in animals exposed to xenobiotics.

\section{Regulation of differentiation}

There are two main mechanisms that eliminate hypertrophic cells. One mechanism is apoptosis, where terminally differentiated cells die. The second mechanism is transdifferentation, where mature chondrocytes are removed by converting them into bone forming cells or osteoblasts [22]. The latter mechanism allows the cells to undergo a drastic change in phenotype and new genes to be expressed [33,34].

On the other hand, there are several molecular, biochemical, as well as morphological changes that take place during differentiation. The growth of bones depends solely on the proliferation and hypertrophy of the chondrocytes located within the growth plate. Apoptosis is also crucial for the terminal chondrocyte maturation, which relies on the secretion of matrix. This process assists in the matrix calcification and is regulated by interactions with various hormones, peptides, and growth factors, which are synthesized locally [33-35].

The key enzymes in apoptosis initiation are caspases, which belong to the cysteine protease family. Caspases are found in the cytoplasm of all cells in the inactive form awaiting a primer to activate apoptosis $[22,35]$. In vitro experiments have shown that chondrocytes with high phosphate concentrations exhibit an increased apoptotic activity [51]. This phenomenon is more common in differentiated than in less differentiated chondrocytes. This increase in phosphate is associated with abnormal mitochondrial function of chondrocytes, which causes a greater reliance on glycolysis with progression towards hypertrophy [52]. 
On the other hand, parathyroid hormone related peptide (PTHrP) is a potent inhibitor of apoptosis, through the mechanism of up-regulation of the apoptosis inhibitor Bcl-2. In addition to phosphate, adverse effects have been seen by glucocorticoids and radiation, which yields and increase in apoptosis [52-55]. In animals treated with a ten-day course of glucocorticoids, an increase of apoptosis in the hypertrophic chondrocytes yields a growth plate with a reduced width was revealed [53]. Both, PTHrH and parathyroid hormone are the main stimulators of the perichondrium. The physiological balance between both factors regulates chondrocytes proliferation and differentiation. Maturation and terminal differentiation also depends on the Indian Hedgehog (Ihh) peptide, which regulates expression of genes coded on the hedgehog receptor and transcriptional factor Gli1 [56,57]. Ihh synthesis begins throughout mesenchymal condensation, increases during cartilage formation and later decreases. Without the factor, the perichondrium transforms into periosteum [59]. Its overexpression up-regulates the expression of perichondrial PTHrP, which keeps chondrocytes in the proliferating state, and slows or even inhibits hypertrophy. Ihh regulates the proportion of chondrocytes dividing and withdrawing from the cell cycle through negative feedback $[60,61]$.

It should be noted, that the periarticular chondrocytes produce PTHrP, but its receptor is found particularly in the prehypertrophic cells and the lower proliferating zone. The mechanism of PTHrP activity is achieved by delaying the hypertrophic differentiation in the lower proliferating zone by maintaining cells in the prehypertrophic phenotype. Secondary to activation of PTH/PTHrP receptors, PTHrP stimulates cell proliferation by $\mathrm{G}$ protein activation and delays their transformation into prehypertrophic and hypertrophic chondrocytes. When proliferation is completed, chondrocytes release Ihh, which stimulates PTHrP synthesis via a feedback loop [56,57].

Transgenic mice lacking PTHrP or its receptor have shown signs of dwarfism caused by the accelerated differentiation and premature hypertrophy. In contrast overexpression of PTHrP causes slower cellular differentiation and a secondary reduction of bone length [61]. In humans, a mutated PTHrP and receptor results in Jansen metaphyseal chondrodysplasia, a dwarfing condition due to a postponement in growth plate mineralization and hypocalcaemia [62].

The next important biological system is related to the thyroid hormone working with major regulatory pathways that govern the proliferation and differentiation of chondrocytes and changes in the ECM $[63,64]$. Thyroxin stimulates type $\mathrm{X}$ collagen synthesis along with other various maturational features through the introduction of BMP-2 [65]. The expression of genes that code these hormones is dependent upon the particular tissue and is regulated at different stages of development. One of the thyroid receptors, TR $\alpha 1$, is predominant in bone, heart, and central nervous system [66]. Deletion of TR $\alpha$ isoform results in stunted linear bone growth, disorganized columnar scaffold of growth plates, lagging cartilage mineralization, and retarded chondrocyte hypertrophy. On the other hand, the deletion of TR $\beta$ did not produce any of these abnormalities [63].

When thyroid hormone is absent or inhibited, the resulting clinical manifestation is hypothyroidism. Relevant symptoms of hypothyroidism in skeletal system include: decreased rate of bone formation, decreased thickness of growth plates of long bones, disorganization of the normal cartilage columns of the growth plates, and hindered differentiation of growth plate chondrocytes into hypertrophic cells [67]. Additionally, it has been noted that the receptor proteins are expressed in reserve and proliferating zone chondrocytes, but not in hypertrophic one in rat growth plate [67]. However, in humans, TR $\alpha 1$ is present in undifferentiated, proliferating, mature and hypertrophic chondrocytes [68].

According to in vitro observations, triiodthyronine (T3) stimulates growth and maturation of porcine scapular and pelvic growth plate cartilage [70]. Its enhancement also causes an increase in mRNA and protein levels of type X collagen, cellular hypertrophy, and alkaline phosphatase activity, which are all indicators of terminally differentiated growth plate chondrocytes $[33,34,64,69]$.

Thyroid hormone is also a modulator of other biological factors. Insulin-like growth facor-1 (IGF-1), for example, is a downstream effector for growth hormone that stimulates the local synthesis of IGF-1 and causes an increase in the rate of cell division [70,71]. In addition, thyroid hormone may be able to act directly on growth plate chondrocytes through growth hormoneindependent mechanisms [34,64]. Further, transgenic mice deficient of the IGF-1 have growth retardation with intense defects in skeleton and various internal organs. This causes death within twenty-four hours after birth [72]. In humans, however, the mutated IGF-1 causes Laron syndrome, characterized by hereditary dwarfism resulting from low serum factor levels [73]. There is also an implication that thyroid hormone could potentially be involved in regulating the set point of the PTHrP-Ihh feedback loop [74]. The hormone enhances FGF signaling that could regulate the inhibitory effects of thyroid hormone on growth plate cell proliferation $[63,75]$.

The effects of thyroid hormone inhibitors have also been studied. Peroxisome proliferator activated receptors (PPARs) are negative regulators of thyroid hormone signaling [76]. PPAR $\gamma$ and ciglitazone - one of its ligands - inhibits thyroid hormone-induced increases in alkaline phosphatase activity by increasing apoptosis. It is believed, that the receptor is one of the few 
negative regulators of thyroid hormone-mediated skeletal growth and gene transcription [63].

It was also observed that thyroid hormone activates Wnt $/ \beta$-catenin signaling in chondrocytes of growth plate. Wnt- 4 activates $\beta$-catenin signaling and encourages terminal differentiation. The main role of $\beta$-catenin is to stimulate differentiation of growth plate chondrocytes and increase alkaline phosphatase activity [64]. When Wnt is inhibited, T3-induced terminal differentiation is blocked and alkaline phosphatase activity is decreased. Based on the above observations, it seems that $\mathrm{T} 3$ stimulates growth plate chondrocyte terminal differentiation by amplifying Wnt- 4 expression, and increasing $\beta$-catenin, TCF/LEF transcriptional activity, and expression of the Wnt/ $\beta$-catenin target gene Runx2/cbfal [64,77].

Iodothyronine deiodinase is another active hormone in the growth plate. An insufficient expression of iodothyronine deiodinase type 2 (DIO2) results in tibial dyschondroplasia, the inability of chondrocytes to undergo terminal differentiation [78]. When $\mathrm{DIO} 2$ is expressed via WSB-1 complex, PTHrP is also presented and chondrocyte differentiation is modulated [63].

Furthermore, just as thyroid hormone is regulated, apoptosis is monitored as well. There are many ways in which apoptosis is monitored or regulated. One of the ways, apoptosis in the growth plate is regulated by balancing the $B c l-2$ protein and an apoptosis inhibitor Bax [79]. If this balance is interrupted, growth plate function is affected and the length of long bones is distorted. The deletion of the $\mathrm{Bcl}-2$ gene accelerates apoptosis of chondrocytes, and causes a decrease in thickness of the growth plate and shortened long bones [80].

One of the most important components in activating apoptosis is the calcium and phosphate $(\mathrm{Pi})$ ion pair [81] that decreases the mitochondrial membrane potential and initiates the process of apoptosis [52]. Pi causes an increase of nitric oxide (NO). Inhibitors of NO synthase and Pi transport cause a decrease in NO concentration, thus preventing cell death [82]. In addition, NO production causes sheer stress, which reduces the expression of type II collagen mRNA and aggrecan [83]. Elevated levels of NO, its synthase (iNOS), and nitrate have been linked to osteoarthritis. In addition, iNOS is expressed when chondrocytes are exposed to cytokines such as IL- 1 and TNF- $\alpha$. IL-1, which is activated by NO, and in turn can inhibit chondrocyte proliferation by acting in conjunction with $\mathrm{PGE}_{2}$, a chondrocyte growth inhibitor [84].

There are two main ways that NO sensitizes chondrocytes to apoptosis: decreases the thiol reserve [86] and affects the survival of the cell under oxidative or nitrosative tension. Furthermore, NO decreases mitochondrial membrane potential, which causes a loss of tight coupling, an essential prerequisite for generating
ATP by means of oxidative phosphorylation. Interference with mitochondrial activity causes a loss of ATP production leading to a low energy state, which makes chondrocytes more susceptible to enter apoptosis [86]. $\mathrm{NO}$ also interferes with cellular adhesion to the extracellular membrane. Chondrocytes depend on adhesion due to survival signals are provided for them by the membrane through matrix interactions and proteoglycans [87]. Similarly, $\beta 1$-integrin-mediated cell matrix interaction gives signals to chondrocytes for survival. The loss of this interaction accompanied by the incapability to respond to IGF-1 can cause osteoarthritis via hypocellularity and matrix degradation [88].

Several other factors are associated with chondrogenesis, i.a., TGF $\beta$, heparan sulfate, fibroblast growth factor receptor-3 (FGFR-3), pleiotrphin/midkine [59].

TGF $\beta$ is an influential inhibitor of maturation, which includes cell hypertrophy, type-X collagen synthesis, and alkaline phosphatase activity. The actions are mediated by Smad-3, which is also a transcription factor $[89,90]$. Studies have illustrated that Smad-3 deficient mice have a normal skeleton at birth, but at three weeks of age, they show signs of cartilage abnormalities, which result in decreased longitudinal growth [91]. PTHrP, Ihh and TGF $\beta$ seem to be the primary regulators of cell proliferation in the growth plate, but other factors such as FGFR-3 also play an important roles $[92,93]$. A mutation in the gene coding the receptor protein results in achondroplasia, which is a dwarfing condition caused by the reduction of proliferation in the growth plate [94].

Heparan sulfate (HSPG) in mouse cartilage is found mainly in proliferating, differentiating, and prehypertrophic chondrocytes, but is reduced in terminally differentiated hypertrophic chondrocytes. Furthermore, HIP/RPL29, a heparan sulfate gene, is up-regulated in carcinomas. Fibronectins are thought to be involved with HSPGs and cartilage integrin $\alpha 5 \beta 1$, influencing cellular morphology [59]. At the moment, there is inadequate evidence regarding the expression of HSPG remodeling enzymes in developing and mature cartilage. However, heparan sulfate is needed for the morphogenesis of individual organs and cartilage formation, which is necessary for skeletal structure $[95,96]$.

\section{Conclusion}

The cartilage growth plate is a highly specialized skeletal structure, essential for bone growth and development. Its formation is a final step of chondrogenesis and is regulated by various factors that modulate cellular proliferation and terminal differentiation, allowing the transformation to apoptotic and autophagal bodies, paralysis, and dark chondrocytes. There is also another highly unknown transdifferentation process in 
which chondrocytes transform into osseous cells. All these mechanisms lead to bone growth and elongation. It is estimated that $60 \%$ of the bone growth is due to chondrocyte hypertrophy, $10 \%$ to cell proliferation and the remainder to matrix synthesis.

Any disturbance of the plate physiology cause developmental abnormalities. For example, the final manifestation of mutations in genes coding specific types of collagen is: Stickler syndrome (collagen type $\mathrm{XI}$ ), Schmid metaphyseal chondrodysplasia (collagen type X) or spondyloepiphyseal and Kniest dysplasia (collagen type II) $[97,98,99]$. Furthermore, abnormalities in IGF1, hedgehog pathway PTHrP and, as well as other important differentiation factors, may induce changes that manifest as dwarfism $[100,101]$. Various pathological factors are also known, while the etiology of other serious growth plate diseases is still unidentified. Intensifications of basic studies will provide prospects for new physiological pathways of the chondrocyte cell cycle and will be helpful in evaluating of such illnesses and their treatments in the future.

\section{References}

[ 1] Melrose J, Smith SM, Smith MM, Little CB. The use of Histochoice for histological examination of articular and growth plate cartilages, intervertebral disc and meniscus. Biotech Histochem. 2008;83:47-53.

[2] Provot S, Schipani E. Fetal growth plate: a developmental model of cellular adaptation to hypoxia. Ann NY Acad Sci. 2007;1117:26-39.

[3] Mau E, Whetstone H, Yu C, Hopyan S, Wunder JS, Alman BA. PTHrP regulates growth plate chondrocyte differentiation and proliferation in a Gli3 dependent manner utilizing hedgehog ligand dependent and independent mechanisms. Dev Biol. 2007;305:28-39.

[4] Erenpresia J, Roach HI. Aberrations of cell cycle and cell death in normal development of the chick embryo growth plate. Mech Ageing Dev. 1999;108:227-338.

[5] DeLise AM, Fischer L, Tuan RS. Cellular interactions and signaling in cartilage development. Osteoarthritis Cartilage. 2000;8:309-334.

[6] Wezeman FH. Morphological foundations of precartilage development in mesenchyme. Microsc Res Tech. 1998;43:91101.

[7] Haas AR, Tuan RS. Chondrogenic differentiation of murine C3H10T1/2 multipotential mesenchymal cells: II. Stimulation by bone morphogenetic protein-2 requires modulation of N-cadherin expression and function. Differentiation. 1999;64: 77-89.

[ 8] Chimal-Monroy J, Díaz de León L. Expression of N-cadherin, N-CAM, fibronectin and tenascin is stimulated by TGFbeta 1 , beta 2 , beta 3 and beta 5 during the formation of precartilage condensations. Int J Dev Biol. 1999;43:59-67.

[ 9] Baserga R, Rubin R. Cell cycle and growth control. Crit Rev Eukaryot Gene Expr. 1993;3:47-61.

[10] Huang W, Zhou X, Lefebvre V, de Crombrugghe B. Phosphorylation of SOX9 by cyclic AMP-dependent protein kinase A enhances SOX9's ability to transactivate a Col2al chondrocyte-specific enhancer. Mol Cell Biol. 2000;20:4149-4158.

[11] Zhang P, Jimenez SA, Stokes DG. Regulation of human COL9A1 gene expression. Activation of the proximal promoter region by SOX9. J Biol Chem. 2003;278:117-123.
[12] Akiyama H, Chaboissier MC, Martin JF, et al. The transcription factor Sox9 has essential roles in successive steps of the chondrocytes differentiation pathway and is required for expression of Sox5 and Sox 6. Genes Dev. 2002;16:28132828.

[13] Eames BF, de la Fuente L, Helms JA. Molecular ontogeny of the skeleton. Birth Defects Res C Embryo Today. 2003;69:93101.

[14] Lefebvre V, Smits P. Transcriptional control of chondrocyte fate and differentiation. Birth Defects Res C Embryo Today. 2005;75:200-212.

[15] Zhao Q, Eberspaecher H, Lefebvre V, de Crombrugghe B. Parallel expression of Sox9 and Col2a1 in cells undergoing chondrogenesis. Dev Dyn 1997;209:377-386.

[16] Abad V, Meyers JL, Weise M, et al. The role of the resting zone in growth plate chondrogenesis. Endocrinology. 2002;143:1851-1857.

[17] Johnstone EW, Leane PB, Kolesik P, Byers S, Foster BK. Spatial arrangement of physeal cartlage chondrocytes and the structure of the primary spongiosa. J Orthop Sci. 2000;5:294301.

[18] Burdan F, Szumilo J, Marzec B, Klepacz R, Dudka J. Skeletal developmental effects of selective and nonselective cyclooxygenase-2 inhibitors administered through organogenesis and fetogenesis in Wistar CRL:(WI)WUBR rats. Toxicology. 2005;216:204-223.

[19] Grimsrud CD, Romano PR, D'Souza M, et al. BMP-6 is an autocrine stimulator of chondrocyte differentiation. $J$ Bone Miner Res. 1999;14:475-482.

[20] Kirsch T, Harrison G, Golub EE, Nah HD. The roles of annexins and type II an X collagen in matrix vesicle-mediated mineralization of growth plate cartilage. J Biol Chem. 2000;275: 35577-35583.

[21] Alvarez J, Balbin M, Fernandez M, Lopez JM. Collagen metabolism is markedly altered in the hypertrophic cartilage of growth plates from rats with growth impairment secondary to chronic renal failure. J Bone Miner Res. 2001;16:511524.

[22] Ballock RT, O'Keefe RJ. Current concepts review: The biology of the growth plate. J Bone Joint Surg. 2003;85A:715-726.

[23] Smits P, Dy P, Mitra S, Lefebvre V. Sox5 and Sox6 are needed to develop and maintain source, columnar, and hypertrophic chondrocytes in the cartilage growth plate. J Cell Biol. 2004; 747-758.

[24] Yoshida CA, Yamamoto H, Fujita T, et al. Runx2 and Runx3 are essential for chondrocytes maturation, and Runx2 regulates limb growth through induction of Indian hedgehog. Genes Dev. 2004;18:952-963.

[25] Takeda S, Bonnamy JP, Owen MJ, et al. Continuous expression of Cbfa1 in nonhypertrophic chondrocytes uncovers its ability to induce hypertrophic chondrocyte differentiation and partially rescues Cbfa1-deficient mice. Genes Dev. 2001;15: 467-481.

[26] Hunziker EB. Mechanism of longitudinal bone growth and its regulation by growth plate chondrocytes. Microsc Res Tech. 1994;28:505-519.

[27] Farnum CE, Wilsman NJ. Converting a differentiation cascade into longitudinal growth: stereology and analysis of transgenic animals as tools for understanding growth plate function. Curr Opin Orthop. 2001;12:428-433.

[28] Kim IS, Otto F, Zabel B, Mundlos S. Regulation of chondrocyte differentiation by Cbfa1. Mech Dev. 1999;80:159-170.

[29] Leboy P, Grasso-Knight G, D'Angelo M, et al. Smad-Runx interactions during chondrocyte maturation. $J$ Bone Joint Surg Am. 2001;83 Suppl 1:S15-22.

[30] Aharinejad S, Marks SC Jr, Bock P, et al. Microvascular pattern in the metaphysic during bone growth. Anat Rec. 1995; 242:111-122. 
[31] Skawina A, Litwin JA, Gorczyca J, Miodonski AJ. The vascular system of human fetal long bones: a scanning electron microscope study of corrosion casts. J Anat. 1994;185:369-376.

[32] Roach HI, Baker JE, Clarke NM. Initiation of the bony epiphysis in long bones: chronology of interactions between the vascular system and the chondrocytes. J Bone Miner Res. 1998;13:950-961.

[33] Ahmed YA, Tatarczuch L, Pagel CN, Davies HM, Mirams M, Mackie EJ. Physiological death of hypertrophic chondrocytes. Osteoarthritis Cartilage. 2007;15:575-586.

[34] Solomon LA, Bérubé NG, Beier F. Transcriptional regulators of chondrocyte hypertrophy. Birth Defects Res C Embryo Today. 2008;84:123-130.

[35] Pucci B, Adams CS, Fertala J, et al. Development of the terminally differentiated state sensitizes epiphyseal chondrocytes to apoptosis through caspase- 3 activation. J Cell Physiol. 2007;210:609-615.

[36] Cummings MC, Winterford CM, Walker NI. Apoptosis. Am J Surg Pathol. 1997;21:88-101.

[37] Roach HI, Aigner T, Kouri JB. Chondroptosis: a variant of apoptotic cell death in chondrocytes? Apoptosis. 2004;9:265277.

[38] Erenpreisa J, Roach HI. Aberrant death in dark chondrocytes of the avian growth plate. Cell Death Differ. 1998;5:60-66.

[39] Roach HI, Erenpreisa J. The phenotypic switch from chondrocytes to bone-forming cells involves asymmetric cell division and apoptosis. Connect Tissue Res. 1996;35:85-91.

[40] Lum JJ, DeBerardinis RJ, Thompson CB. Autophagy in metazoans: cell survival in the land of plenty. Nat Rev Mol Cell Biol. 2005;6:439-448.

[41] Lum JJ, Bauer DE, Kong M, et al. Growth factor regultion of autophagy and cell survival in the absence of apoptosis. Cell. 2005; 120:237-248

[42] Phornphutkul C, Wu KY, Auyeung V, Chen Q, Gruppuso PA. mTOR signaling contributes to chondrocyte differentiation. Dev Dyn. 2008;237:702-712.

[43] Roach HI, Clarke NM. Physiological cell death of chondrocytes in vivo is not confined to apoptosis. New observations on the mammalian growth plate. J Bone Joint Surg Br. 2000; 82:601-613.

[44] Roach HI, Clarke NM. "Cell paralysis" as an intermediate stage in the programmed cell death of epiphyseal chondrocytes during development. J Bone Miner Res. 1999;14:13671378.

[45] Ghadially FN. The dark-light cell phenomenon. In: Ultrastructural pathology of the cell and matrix. New York, Butterworth-Heinemann: 1997:954-961.

[46] Hwang WS. Ultrastructure of human foetal and neonatal hyaline cartilage. J Pathol. 1978;126:209-214.

[47] Silbermann M, Frommer J. Heterogeneity among chondrocytes of the mandibular condyle in foetal and postnatal mice. Arch Oral Biol. 1973;18:1549-1554.

[48] Wilsman NJ, Farnum CE, Hilley HD, Carlson CS. Ultrastructural evidence of a functional heterogeneity among physeal chondrocytes in growing swine. Am J Vet Res. 1981;42:15471553.

[49] Solecki M. Evaluation of TNF gene expression and morphology of epiphyseal cartilage in rat offsprings exposed to cyclooxygenase inhibitors ( $\mathrm{PhD}$ Thesis) Lublin: Medical University of Lublin; 2007.

[50] Mansfield K, Rajpurohit R, Shapiro IM. Extracellular phosphate ions cause apoptosis of terminally differentiated epiphyseal chondrocytes. J Cell Physiol. 1999;179:279-86

[51] Rajpurohit R, Mansfield K, Ohyama K, Ewert D, Shapiro IM. Chondrocyte death is linked to development of a mitochondrial membrane permeability transition in the growth plate. J Cell Physiol. 1999;179:287-96

[52] Silvestrini G, Ballanti P, Patacchioll FR, et al. Evaluation of apoptosis and the glucocorticoid receptor in the cartilage growth plate and metaphyseal bone cells of rats after high dose treatment with corticosterone. Bone. 2000;26:33-42.

[53] Pateder DB, Eliseev RA, O'Keefe RJ, et al. The role of autocrine growth factors in radiation damage to the epiphyseal growth plate. Radiat Res. 2001;155:847-857.

[54] Hilton MJ, Tu X, Long F. Tamoxifen-inducible gene deletion reveals a distinct cell type associated with trabecular bone, and direct regulation of PTHrP expression and chondrocyte morphology by Ihh in growth region cartilage. Dev Biol. 2007;308:93-105.

[55] St-Jacques B, Hammerschmidt M, McMahon AP. Indian hedgehog signaling regulates proliferation and differentiation of chondrocytes and is essential for bone formation. Genes Dev. 1999;13:2072-286.

[56] Sakamoto A, Chen M, Nakamura T, Xie T, Karsenty G, Weinstein LS. Deficiency of the G-protein alpha-subunit G(s)alpha in osteoblasts leads to differential effects on trabecular and cortical bone. J Biol Chem. 2005;280:21369-21375.

[57] Sakamoto A, Chen M, Kobayashi T, Kronenberg HM, Weinstein LS. Chondrocyte-specific knockout of the $G$ protein G(s)alpha leads to epiphyseal and growth plate abnormalities and ectopic chondrocyte formation. J Bone Miner Res. 2005; 20:663-671.

[58] Chung UI, Schipani E, McMahon AP, Kronenberg HM. Indian hedgehog couples chondrogenesis to osteogenesis in endochondral bone development. J Clin Invest. 2001;107:295-304.

[59] Kirn-Safran CB, Gomes RR, Brown AJ, Carson DD. Heparan sulfate proteoglycans: coordinators of multiple signaling pathways during chondrogenesis. Birth Defects Res C Embryo Today. 2004;72:69-88.

[60] Lai LP, Mitchell J. Beta2-adrenergic receptors expressed on murine chondrocytes stimulate cellular growth and inhibit the expression of Indian hedgehog and collagen type X. J Cell Biochem. 2008;104:545-553.

[61] Schipani E, Lanske B, Hunzelman J, et al. Targeted expression of constitutively active receptors for parathyroid hormone and parathyroid hormone-related peptide delays endochondral bone formation and rescues mice that lack parathyroid hormone related peptide. Proc Natl Acad Sci USA. 1997; 94:13689-13694.

[62] Schipani E, Langman CB, Parfitt AM, et al. Constitutively activated receptors for parathyroid hormone and parathyroid hormone-related peptide in Jansen's metaphyseal chondrodysplasia. N Engl J Med. 1996;335:708-714.

[63] Shao YY, Wang L, Ballock RT. Thyroid hormone and the growth plate. Rev Endocr Metab Disord. 2006;7:265-271.

[64] Wang L, Shao YY, Ballock RT. Thyroid hormone interacts with the Wnt/beta-catenin signaling pathway in the terminal differentiation of growth plate chondrocytes. $J$ Bone Miner Res. 2007;22:1988-1995.

[65] Ballock RT, Mink LM, Chen DH, Mita BC. Thyroid hormone regulates terminal differentiation of growth plate chondrocytes through local induction of bone morphogenic proteins. Trans Orthop Res Soc. 2000;25:160.

[66] Van Vliet G, Larroque B, Bubuteishvili L, Supernant K, Leger J. Sex-specific impact of congenital hypothyroidism due to thyroid dysgenesis on skeletal maturation in term newborns. $J$ Clin Endocrinol Metab. 2003;88:2009-2013.

[67] Stevens DA, Hasserjian RP, Robson H, Siebler T, Shalet SM, Willaims GR. Thyroid hormones regulate hypertrophic chondrocyte differentiation and expression of parathyroid hormone-related peptide and its receptor during endochondral bone formation. J Bone Miner Res. 2000;15:24312442.

[68] Abu EO, Horner A, Teti A, Chatterjee VK, Compston JE. The localization of thyroid hormone receptors mRNAs in human bone. Thyroid. 2000;10:287-293. 
[69] Burch WM, Van Wyk JJ. Triiodothyronine stimulates cartilage growth and maturation by different mechanisms. $\mathrm{Am} \mathrm{J}$ Physiol. 1987;252:E176-182.

[70] Ohlsson C, Isgaard J, Tornell J, Nilsson A, Isaksson OG, Lindahl A. Endocrine regulation of longitudinal bone growth. Acta Paediatr. 1993;391 Suppl 92:33-41.

[71] Wang Y, Nishida S, Sakata T, et al. Insulin-like growth factorI is essential for embryonic bone development. Endocrinology. 2006;147:4753-4761.

[72] Liu JP, Baker J, Perkins AS, Robertson EJ, Efstratiadis A. Mice carrying null mutations of the genes encoding insulinlike growth factor I (Igf-1) and type 1 IGF receptor (IGF1r). Cell. 1993;75:59-72.

[73] Uckun-Kitapci A, Haqq AM, Purnell JQ, Newcomb K, Gulkesen H, Underwood LE. Serum ghrelin concentrations are increased in children with growth hormone insensitivity and decrease during long-term insulinlike growth factor-I treatment. J Investig Med. 2008;56:26-31.

[74] Vortkamp A, Lee K, Lanske B, Segre GV, Kroneberg HM, Tabin CJ. Regulation of rate of cartilage differentiation by Indian hedgehog and PTH-related protein. Science. 1996;273: 613-622.

[75] Krejci P, Krakow D, Mekikian PB, Wilcox WR. Fibroblast growth factors 1, 2, 17, and 19 are the predominant FGF ligands expressed in human fetal growth plate cartilage. Pediatr Res. 2007;61:267-272.

[76] Araki O, Ying H, Furuya F, Zhu X, Cheng SY. Thyroid hormone receptor beta mutants: dominant negative regulators of peroxisome proliferators-activated receptor gamma action. Proc Natl Acad Sci U S A. 2005;102:16251-16256.

[77] Andrade AC, Nilsson O, Barnes KM, Baron J. Wnt gene expression in the post-natal growth plate: regulation with chondrocyte differentiation. Bone. 2007;40:1361-1369.

[78] Shen S, Berry W, Jaques S, Pillai S, Zhu J. Differential expression of iodothyronine deiodinase type 2 in growth plates of chickens divergently selected for incidence of tibial dyschondroplasia. Anim Genet. 2004;35:114-118.

[79] Wang Y. Toury R, Hauchecorne M, Blamain N. Expression of $\mathrm{Bcl}-2$ protein in the epiphyseal plate cartilage and trabecular bone of growing rats. Histochem Cell Biol. 1997;108:45-55.

[80] Amling M, Neff L, Tanaka S, et. al. Bcl-2 lies downstream of parathyroid hormone-related peptide in signaling pathway that regulates chondrocyte maturation during skeletal development. J Cell Biol. 1997;136:205-213.

[81] Magne D, Bluteau G, Faucheux C, et al. Phosphate is a specific signal for ATDC5 chondrocyte maturation and apoptosis-associated mineralization: possible implication of apoptosis in the regulation of endochondral ossification. $J$ Bone Miner Res. 2003;18:1430-1442.

[82] Teixeira CC, Ischiropoulos H, Leboy $\mathrm{P}$, et al. Nitric oxidenitric oxide synthase regulates key maturational events during chondrocyte terminal differentiation. Bone. 2005;37:37-45.

[83] Lee MS, Trindade MCD, Ikenoue T, Schurman DJ, Goodman SB, Smith RL. Effects of shear stress on nitric oxide and matrix protein gene expression in human osteoarthritic chondrocytes in vitro. J Orthop Res. 2002;20:556.

[84] Blanco FJ, Oschs RL, Schwar H, Lotz M. Chondrocyte apoptosis induced by nitric oxide. Am J Pathol. 1995;146:75-85.

[85] Teixeira CC, Rajpurohit R, Mansfield K, et al. Maturationdependent thiol loss increases chondrocyte susceptibility to apoptosis. J Bone Miner Res. 2003;18:662-668.

[86] Teixeira CC, Mansfield K, Hertkorn C, et al. Phosphate induced chondrocyte apoptosis is linked to nitric oxide generation. Am J Physiol Cell Physiol. 2001;281:C833-C839.
[87] Cao L, Lee V, Adams ME, Kiani C, Zhang YO, Hu W, Yang BB. $\beta 1$-Integrin-collagen interaction reduces chondrocyte apoptosis. Matrix Biol. 1999;18:343-355.

[88] Mobasheri A, Carter SD, Martin-Vasallo M, Shakibaei M. Integrins and stretch activated ion channels; putative components of functional cell surface mechanoreceptors in articular chondrocytes. Cell Biol Int. 2002;26:1-18.

[89] Ferguson CM, Schwarz EM, Reynolds PR, Puzas JE, Rosier RN, O'Keefe RJ. Smad2 and 3 mediate transforming growth factor-beta1 induced inhibition of chondrocyte maturation. Endocrinology. 2000;141:4728-4735.

[90] Pateder DB, Ferguson CM, Ionescu AM, et al. PTHrP expression in chick sterna chondrocytes is regulated by TGF-beta through Smad-mediated signaling. J Cell Physiol. 2001;188: 343-351.

[91] Pedrozo HA, Schwartz Z, Gomez R, et al. Growth plate chondrocytes store latent transforming factor (TGF)-beta 1 in their matrix through latent TGF-beta 1 binding protein-1. J Cell Physiol. 1998;177:343-354.

[92] Colvin JS, Bohne BA, Harding GW, McEwen DG, Ornitiz DM. Skeletal over-growth and deafness in mice lacking fibroblast growth factor receptor 3. Nat Genet. 1996;12:390397.

[93] Deng C, Wynshaw-Boris A, Zhou F, Kuo A, Leder P. Fibroblast growth factor receptor 3 is a negative regulator of bone growth. Cell. 1996;84:911-921.

[94] Vajo Z, Francomano CA, Wilkin DJ. The molecular and genetic basis of fibroblast growth factor receptor 3 disorders: the achondroplasia family of skeletal dysplasias, Muenke craniosynostosis, and Crouzon syndrome with acanthosis nigricans. Endocr Rev. 2000;21:23-39.

[95] Perrimon N, Bernfield M. Specificities of heparan sulphate proteoglycans in developmental processes. Nature. 2000; 404:725-728

[96] Princivalle M, de Agostini A. Developmental roles of heparan sulfate proteoglycans: a comparative review in Drosophilia, mouse and human. Int J Dev Biol. 2002;46: 267-278.

[97] Horton WA, Hecht JT. The chondrodysplasias. In: Royce PM, Steinmann B, eds. Connective tissue and its heritable disorders: molecular, genetic, and medical aspects. New York, Wiley-Liss; 1993:641-675.

[98] Holden P, Canty EG, Mortier GR, et al. Identification of novel pro-alpha2(IX) collagen gene mutations in two families with distinctive oligo-epiphyseal forms of multiple epiphyseal dysplasia. Am J Hum Genet. 1999;65:31-38.

[99] Sirko-Osadsa DA, Murray MA, Scott JA, Lavery MA, Warman ML, Robin NH. Stickler syndrome without eye involvement is caused by mutations in COL11A2, the gene encoding the alpha2(XI) chain type XI collagen. $J$ Pediatr. 1998;132:368-371.

[100] Kimura H, Ng JM, Curran T. Transient inhibition of the Hedgehog pathway in young mice causes permanent defects in bone structure. Cancer Cell. 2008 Mar;13(3):249-260.

[101] Rimoin DL, Cohn D, Krakow D, Wilcox W, Lachman RS, Alanay Y. The skeletal dysplasias: clinical-molecular correlations. Ann NY Acad Sci. 2007;1117:302-309.

Submitted: 14 October, 2008 Accepted after reviews: 4 December, 2008 